\title{
ESCOLA DIFERENCIADA GUARANI: ENTRE O VIVER SEMINAL E O VIVER OCIDENTAL
}

\author{
R. M. O. VIÇOSA* e A. L. T. MENEZES \\ Universidade De Santa Cruz do Sul - UNISC \\ espacozenso@gmail.com*
}

Artigo submetido em setembro/2014 e aceito em dezembro/2015

DOI: $10.15628 /$ holos.2015.2430

\section{RESUMO}

A construção das escolas diferenciadas da tradição Guarani tem representado um desafio para suas aldeias no interior do Rio Grande do Sul, bem como para as escolas rurais que acompanham esse processo e as universidades envolvidas. Partindo da observação e convivência com duas aldeias indígenas, a de Estrela Velha e a de Salto do Jacuí (investigando infâncias e educação Guarani), encontramos três escolas: a Escola Estadual Indígena de Ensino Fundamental Guarani, em Salto do Jacuí; a Escola Estadual Indígena de Ensino Fundamental Karaí Tata Endy Vera Claudio Acosta, em Estrela Velha, e profissionais da Escola Itaúba, situada no município de Estrela Velha, na qual possuem 6 estudantes indígenas. As duas primeiras estão sendo construídas nas aldeias e trabalham até o quinto ano do Ensino Fundamental. Enquanto são construídas, as crianças saem para escolas não indígenas. Em ambas as escolas diferenciadas, existem professores indígenas e não indígenas que ensinam principalmente língua Guarani, Português e Matemática, situadas no interior do Rio Grande do Sul. Nesse processo, nas duas aldeias, estão implicados lideranças indígenas, crianças e jovens das aldeias, professores Guarani e não indígenas, diretores da rede Estadual de Educação, Karai ${ }^{1}$ e KunhãKarai, estudantes e pesquisadores do Mestrado em Educação da Universidade de Santa Cruz - UNISC/RS², que juntos desenvolvem uma pesquisa-ação e etnográfica que vem acontecendo desde o início de 2013 de modo compartilhado e negociado através do diálogo e da escuta do que pensamos e queremos como escola diferenciada em cada aldeia Guarani. Apresentaremos as observações e diálogos que emergem do pesquisar conjuntamente e que produziram reflexões teóricas acerca do pensar, do viver seminal e ocidental.

PALAVRAS-CHAVE: escola diferenciada, educação Guarani, pensamento seminal

\section{DIFFERENCIATED GUARANI SCHOOLS: ASPECTS CONCERNING SEMINAL AND OCCIDENTAL LIVING}

\section{ABSTRACT}

Constructing different Guarani schools has been a challenge for the Guarani villages in the countryside of Rio Grande do Sul, country schools and universities involved in this matter. As we were in two indigenous villages located in Estrela Velha e Salto do Jacuí, investigating about childhood and Guarani education, we found three different schools: Escola Estadual Indígena de Ensino Fundamental Guarani located in Salto do Jacuí, Escola Estadual Indígena de Ensino Fundamental Karaí Tata Endy Vera Claudio Acosta located in Estrela Velha and many professionals who work for Escola Itaúba. The last one is situated in Estrela Velha/RS and has six indigenous students. The first two schools mentioned here are being built inside indigenous villages and hold up to fifth grade, grade, in which, children have to go to a nonindigenous school. In both schools there are indigenous and non-indigenous teachers responsible for teaching, mostly,
\end{abstract}

Guarani language, Portuguese language and math. In this process, inside both villages, there are many people involved: indigenous leaders, children and young adults from the villages, Guarani and non-indigenous teachers, principals from Karai and Kunhã Karai state schools, students and researchers from the Master's program in Education from the University of Santa Cruz do Sul UNISC/RS. Our group develops an action and ethnographic research there since 2013. This inquiry is based on shared experiences and dialogues about what we understand and want for those differentiated schools inside each indigenous village. We present here the notes and dialogue which result from our collective study and have produced theorical reflections concerning seminal and occidental thinking and living.

KEYWORDS: differentiated school, Guarani education, seminal thoughts. ${ }^{1}$ Liderança espiritual com poderes de cura. Karaí é masculino e
kunhãkaraí é o feminino.
${ }^{2}$ Através da linha de pesquisa Aprendizagem, tecnologias $e$ linguagens na educação vinculada ao grupo de pesquisa LinCE Linguagens, Cultura e Educação - UNIAC/CNPq. 


\section{EDUCAÇÃO E ESCOLA DIFERENCIADA}

Ao aprofundarmos o trabalho de pesquisa de campo, acerca da infância e da educação Guarani, na aldeia de Estrela Velha e do Salto do Jacuí, ambas situadas no interior do Rio Grande do sul, compreendemos melhor a relação entre a escola diferenciada e o sentido de educação para os Guarani. A pesquisa, que está sendo realizada desde 2013 e sendo financiada pela FAPERGS, através do Edital pesquisador Gaúcho e pela Universidade de Santa Cruz do Sul, é vinculada ao Departamento de Psicologia e ao Mestrado de Educação. A metodologia é etnográfica e da pesquisa-ação, que exige das pesquisadoras uma participação efetiva, um olhar atento ao contexto e uma construção conjunta com os indígenas que fazem parte desse estudo como pesquisadores de suas próprias realidades.

Educação Guarani é definida "como pedagogia em um processo orientado para a consecução de um modo de ser e de um projeto de identidade: o Guarani" (MELIÁ, 2010, p.37). O processo de educação é formar um "bom Guarani", buscando uma perfeição através da reza, da dança e do canto.

[...] o núcleo inicial da pessoa é a "palavra" ayvu (ou ñe'ë), porção divina por participação; palavra-alma que, por sua própria origem, está destinada a voltara um dos Pais de quem procede; é boa e indestrutível. Outras "almas" serão a "sombra" (ã); a "paixão" (asyguá), que tem algo de gênio animal encarnado; ou o "modo de ser imperfeito": (tekoachý), com suas manifestações de mau caráter, agressividade ou simples condição telúrica ou corporal (MELIÁ, 2010, p. 40).

Educar para os Guarani significa garantir o crescimento da palavra-alma, principalmente no primeiro ano de vida e que vai sendo cultivado ao longo da vida, a partir da compreensão do ñandereko, do modo de ser Guarani.

A clareza dos Guarani, frente ao seu modo de educar, permite uma delimitação no processo de construção das escolas diferenciadas em suas aldeias que consiste na busca de aprendizagem do modo de vida não indígena, que inclui basicamente o aprendizado da língua portuguesa e dos códigos de comunicação intercultural. Para Bergamaschi (2013) a escola diferenciada representa um querer e um não querer indígena, no sentido de ser um processo complexo, dinâmico e fluido. A escola diferenciada é a oportunidade de legitimar a pedagogia ritualística quando oportuniza que as mesmas façam parte do currículo. Os Guarani estão sempre atentos, acerca do que deve e do que não deve constar na escola, enquanto conteúdo e metodologia. Estes não buscam, por exemplo, fazer rituais e tocar em temas religiosos dentro da escola, tendo em vista que o fazem na Opy, casa de reza, que consideram ser sua verdadeira universidade.

Percebemos o quanto a escola diferenciada nas aldeias tem representado um espaço de troca e de educação intercultural, que tem mobilizado tanto os professores indígenas e não indígenas para aprendizados que refletem modos de vidas diferenciados.

O desafio educacional, após a Constituição de 1988, em assegurar o direito às sociedades indígenas brasileiras a uma educação escolar diferenciada, específica, intercultural e bilíngue, está em enfrentar um campo de estudos e formação que contemple a alteridade nas formas escolares, consequentemente, nas diversas cosmologias e modos próprios de viver e pensar indígena. 
Nesse sentido é que concebemos parte de nossa pesquisa como um caminho percorrido de aproximação entre a educação Ameríndia e a educação escolarizada ocidental, na possibilidade de um diálogo intercultural e intercientífico. Surgem reflexões acerca do pensamento seminal presente na educação Guarani, o quanto este pode transitar, lado a lado, com o pensamento lógico cartesiano ocidental, embasados em um pensar próprio da América na construção da escola diferenciada ${ }^{3}$.

A pesquisa com os índios Guarani tem representando uma entrega total, no sentido de voltar a considerar o conhecimento desde as condições vivas da realidade do mundo e de nossa própria realidade psíquica, desde a consideração de um homem concreto, sensível e não puramente intelectual. Ser humano que se relaciona com uma realidade igualmente concreta e viva, como um corpo inteiro que sente, cuida, fala e age (PINHO, 2003). É um processo de estarsendo, que sugere um constante caminhar ( $\mathrm{KUSCH}, 2008)$. A pesquisa se dá no caminhar: caminhando e dialogando.

A escola diferenciada na aldeia indígena defende princípios da autonomia, interculturalidade e cidadania integral do índio Guarani. Escola que traz consigo uma flexibilidade de currículo, com calendários que respeitam as festas, vendas de artesanato e colheitas; suas formas tradicionais, com espaços e tempos próprios, com horários diferenciados para professores indígenas, conforme a fala da Diretora da Escola Guarani, de Estrela Velha, Marilei Hass. Ela afirma que o calendário das aulas é encerrado na primeira semana de dezembro, respeitando a época de venda de artesanato Guarani.

Podemos falar de um aprendizado de diálogo intercultural que reforça a necessidade de mudanças em nosso sistema educacional, como a burocracia e o engessamento na área da gestão educacional. Tal diálogo tem provocado nas secretarias e departamentos de estado, novas políticas de tratamento, atendendo a particularidades de cada comunidade indígena numa perspectiva intercultural. Por seu turno, esse diálogo tem gerado conflitos e ao mesmo tempo, novas oportunidades no campo das ideias e da operacionalização. Um exemplo dessa experiência está sendo a discussão do projeto político pedagógico da escola na aldeia de Estrela Velha, que requer um sentar, um dialogar e um escrever juntos, representando formas alternativas de construção metodológicas e políticas nas escolas diferenciadas.

\section{O VIVER SEMINAL E O VIVER OCIDENTAL}

Entre os aspectos que gostaríamos de ressaltar, nessa relação intercultural que envolve as aldeias e a construção das escolas diferenciadas, é o da aceitação do pensamento seminal como ciência ou como conhecimento acadêmico, ao lado do pensamento lógico-cartesiano ocidental. E os potenciais são expressos na forma como os educadores e gestores públicos têm percebido e se transformado, a partir das experiências vividas e pensadas.

Para melhor entendermos os conceitos de pensamento seminal e pensamento ocidental, se faz necessário um pouco de história, tanto na sua dimensão teórica como a que estamos vivenciando nas aldeias.

\footnotetext{
${ }^{3}$ Escola Diferenciada é a nomenclatura usada na Resolução n. 05/2012 do CNE/CNB, que se refere à escola de Aldeia.
} 
Gunther Rodolfo Kusch- Pensador, filósofo, antropólogo pensou a América de uma forma profunda, considerou a contemplação, a intuição, o andar junto com o campesino, com o indígena e com o Andino, para fundamentar sua crítica ao pensamento hegemônico ocidental do séc. XIX. Trouxe uma nova filosofia pensada e posicionada a partir da América. Uma filosofia de posicionamento coletivo.

Como filho de imigrante, Kusch em casa recebia ensinamentos europeus, hegemônicos, mas vivia na América, sua raiz era americana. Vivia um constante conflito entre o ser europeu e o estar enraizado em solo americano. E por isso a leitura de sua obra enquanto militante é diferente da leitura enquanto teórico. Visto que o objetivo do teórico responde a uma necessidade localizada de fora do lugar. É o olhar do observador, geralmente de um espaço de limpeza epistêmica e sujeito ao tempo da academia, que não está vinculada a necessidade das pessoas, do objeto.

A educação como um todo, num modelo escolar de universalismos e conjunturas ocidentais, evidenciavam os índios nos livros acadêmicos de forma muito estereotipada, pintado e com cocares em uma aldeia com ocas de taquara e barro. Observamos que quando alguns estudantes visitavam as aldeias pesquisadas, geralmente são impactados por um misto de emoções e frustrações pela quebra do paradigma aprendido.

As reflexões trazidas por Kusch apresentam novos modos epistemológicos e ontológicos de pensar o conhecimento e passa a refletir, a partir da experiência vivida, sentindo o "fedor" da América (MIGNOLO. 2013).

Na primeira reunião entre os participantes da pesquisa na aldeia indígena no Salto do Jacuí compreendemos o que Kusch (2012) reflete acerca do "fedor":

\footnotetext{
“...preocupava-me com a sujeira que ficaria nas cadeiras, o barro que impregnava nos móveis e que voltaria para dentro da sala de aula, pois utilizávamos as cadeiras da sala de aula para nos sentar em círculo e conversar a cerca dos pontos da pesquisa. E, quando vi as crianças comendo livres, caminhando e se arrastando no chão sujo, úmido, visto que chovia uma garoa fina, senti ímpetos de cuidar, limpar, procurar calcados para colocar nos pés que estavam apenas com meias no barro" (RAQUEL VIÇOSA, diário de campo, 2013).
}

O ensinamento que nos é dado na escola tradicional e na família, dentro desse modelo universal e construído a partir do pensamento hegemônico Ocidental Europeu, de pura assepsia, de frieza e necessidade de controlar e não expressar nossas emoções, fica visível quando nos encontramos com a cultura ameríndia, uma cultura da América.

\footnotetext{
"Percebi também o quanto eles vivem na natureza sem se preocupar com a limpeza da aldeia ou seu entorno. A preocupação com o meio ambiente é diferente, é de uma forma "sustentável", do que nos é ensinado. No caminho para a cachoeira eu vi sistemas vivos (algas, musgos) intocados, e ao mesmo tempo encontrava pelo caminho roupas espalhadas, que deveriam ter sido esquecidas ou perdidas lá que eles nem se preocupavam em busca-las" (RAQUEL VICOSA, diário de campo, 2013).
}

Aos poucos, aprofundando nossas vivências com a cultura Guarani, percebemos que não se trata de buscar a negação de um pensamento em detrimento do outro. Pretende-se tornar possível a reflexão e o entrecruzamento entre um e outro pensamento. Permitir o andar junto e 
uma dialética do antagonismo, possibilitando uma critica à hegemonia de um pensamento sobre outro. Impedir a subalternidade do conhecimento indígena e o exercício à diferença e à coexistência de pensamentos denominados ocidental e seminal.

A leitura de Kusch (1999) responde a uma proposta de transformação que o envolve pela afetação do lugar e que exige respostas imediatas aos problemas de cada dia.

E são respostas que tem que ver com o aqui e agora das pessoas, com a decisão cultural que se expressa em suas estratégias de vida e com o direito arraigado em um solo em que às vezes bastam duas chapas e uma manta para sentir o direito arraigado e brigar por ele (FLORENCIA KUSCH, 2013, p.95).

A transcendência, nesta forma de pensar a pesquisa, não está relacionada com a possibilidade de aplicar suas categorias de análises, que seria o papel da ciência ou da filosofia, e sim, que devemos ir além, e pensar, no mais profundo do pensamento de Kusch, quando nos faz pensar acerca de uma ciência construída a partir de um pensar e viver seminal. Esta vem de uma lógica ritualística, mística, intuitiva, vivida e sentida no estar sendo diário da aldeia onde a espiritualidade é a ética que direciona tal pensamento.

Certa vez, em campo de pesquisa, na aldeia Estrela Velha, uma coordenadora de uma das Coordenadorias de Educação do Estado, em momento de formação de professores indígenas e não indígenas, revela seus temores: "eu tinha medo do embranquecimento, eu não sabia para quê a escola, quando se referiu à escola nas aldeias indígenas". Nessa fala percebe-se o cuidado com que todo o processo está sendo tratado e a necessidade de aprofundamento das questões vividas e o medo do pensamento ocidental se sobrepor ao seminal.

Eduardo Acosta, professor Guarani, chama a atenção para o fato de que as crianças Guarani aprendem o Português na escola Indígena, mas quando vai para a escola não indígena, não consegue se relacionar de uma forma clara. João Acosta, cacique de Estrela Velha, indaga "o que acontece com o aluno Guarani na escola que ele não pergunta?"

Nossa cultura é diferente. Nosso aluno é tímido. Ele não fala. Isso é o problema. Ele estudou a primeira língua Guarani. Os professores da escola Itaúba tratam iguais os alunos, eles deveriam tratar diferente, dar mais oportunidade. Os Guarani ouvem mais e falam menos. Aqui eles têm todo o tempo. Os Guarani sabem matemática, mas não aplicação, num ritmo diferente. Eles são assíduos e querem aprender. $O$ difícil é trabalhar o diferencial da cultura (ANA LUISA MENEZES, diário de campo, 2013).

Questionamentos como estes têm provocado, em todos os envolvidos e, principalmente, nos professores e diretores das escolas, a discussão de um fazer pedagógico que empodere 0 Guarani na coragem para falar, partindo de uma transição, de um acolhimento e de um conhecimento do que Kusch (2012) define como pensamento seminal, que é intuitivo, visceral, enraizado nas terras originárias do sul, nos saberes da $\mathrm{Opy}^{4}$, com seus mitos, símbolos e ritos.

Para o autor, não olhar para essa dimensão reforça uma educação falseada:

\footnotetext{
${ }^{4}$ Nome em Guarani para a Casa de Rezas na Aldeia.
} 
... que a cultura ocidental se ergueu sobre o "escamoteo" e não sobre a superação da vida emocional, ou seja, para evitar-se enfrentar o problema, sufoca-se, controla, as emoções para alcançar o objetivo da produtividade, é uma negação, um não expressar, da emoção ao fim da livre ação da inteligência (KUSCH. 2012,p.56).

\section{FAGOCITAÇÃO GUARANI: ESTAR SENDO ESCOLA}

Deparando-nos na escola diferenciada com tamanhas divergências de pensamento. Encontramos, no conceito de Kusch (1999) da fagocitose, como processo pelo qual um organismo engloba e engole o corpo estranho, digerindo-o e gerando energia para continuar a vida. De um lado há um receio, de outro e ao mesmo tempo, acreditando que novas compreensões possam emergir nessa aproximação de pensamentos.

A escola tradicional tem suas convenções próprias vindas do Ocidente, dentro de um espaço próprio, com carteiras lineares, ritos e tempos próprios. Já a escola vivida e experienciada na aldeia, onde os tempos, modos e ritos são próprios de sua cosmovisão e, a partir dela, constroem sua ciência no seu processo de leitura de mundo. Nesse processo da fagocitação não há possibilidade de dois organismos diferentes persistirem coabitando num mesmo corpo, num mesmo habitat, mas há a possibilidade de transformação.

Indagações surgem no meio do caminho que revelam possibilidades de novas formas de viver a escola: será que há lugar para diferentes pensamentos? Ou o estranho será fagocitado pelo originário? E quem é o estranho e quem é o originário na implementação da escola diferenciada? Perguntas que não conseguimos responder de uma forma definitiva, mas que servem de motivos de diálogos e ações conjuntas.

Kusch (1999) em sua obra América Profunda, traz o conceito de fagocitação como sendo um processo inverso ao processo de aculturação. Ou seja, fagocitação é tida como um feito universal, se produz no invisível, no intimo, no ser. A aculturação se produz no estar, no exterior, no material. Não é um processo nem bom nem ruim, é o próprio risco do caminhar.

A implantação da escola diferenciada na aldeia representa um encontro intercultural entre indígenas e não indígenas, do que pode ser construído. Podemos falar de uma fagocitação, no qual o indígena e o não indígena modificam-se e produzem algo novo, que respeita as particularidades de cada cultura. Kusch (1999) refere que para o indígena, a fagocitose é natural, e tem nesse entendimento uma vantagem de entender que tudo é passageiro. Os indígenas trazem o conhecimento de que o ser alguém é transitório e de nenhum modo é imutável e eterno.

Desta forma, compreendemos a vivência dos Guarani de um estar sendo escola, não como uma adaptação à escola ocidental, mas como uma transformação do sentido de escola, na medida em que os Guarani vão transformando os modos de organização escolar tradicional. Nos diálogos que vamos trazendo ao longo dos textos, podemos perceber o quanto os Guarani têm refletido e construído modos inventivos de ser escola.

Os indígenas compreendem que o caos é importante para a aprendizagem, e que na interação é que se dá a construção do outro:

Ademais, a construção do outro se dá num processo de negociação onde cultura e identidades culturais estão em uma continua efervescência, como espaços 
inscritos e como historia de atores sociais dentro de uma temporalidade (MACEDO, 2004, p.55).

O medo de que o índio seja engolido pelo branco, ou seja, o medo de que a escola tradicional fagocite o modelo escolar indígena, que possui outros modos, outros tempos, é um caminhar limítrofe entre o Ser alguém e o estar-sendo. Contudo, está sendo refletido pelos Guarani a partir da apropriação de suas histórias, conforme explicita João: "apressar demais o pessoal vai fazer desistir e ir embora, como foi o meu caso." No momento de discussão foi colocado também o caso da Michele, jovem Guarani que estava sendo considerada como aluna fraca por uma professora da Escola Itaúba, mesma oportunidade em que era também de formação de professores indígenas e não indígenas da 24ạ. e 9ạ. CRE, do Estado do Rio Grande do Sul. Todos refletiram sobre o quanto Michele era na verdade uma aluna "forte", em condições de aprender e interagir, pois tinha sido encaminhada da 5 à à 7ạ. série sem ter feito a 6a.., garantindo que estivesse com os outros Guaranis, já que todos esses estavam na 7ạ. Série.

Essas e outras questões reforçam a palavra do cacique João, que afirma que não sabem direito sobre a escola e que escolas querem construir. Nas palavras do Márcio, professor da Escola de Salto do Jacuí: "nós não temos escola diferenciada. O Estado não reconhece a educação diferenciada. Calendário diferenciado? Que escola funciona assim?"

O que temos visto na Aldeia é que os Guarani sentiram a necessidade de aprofundar conhecimentos acerca de nossa cultura, enfrentando o medo, empoderando-se e mergulhando de todo, na implementação da escola diferenciada. Aldeia que sente ter chegado ao caos, no sentido de ver na escola diferenciada um aprendizado que vem na defesa da sua sobrevivência, neste mundo homogeneizado de verdades absolutas e rígidas, de conceitos e conjunturas universais. 0 Guarani se auto-organiza frente ao caos e se mantém firme e flexível. Ele tem na sua fé, nas suas crenças, algo para se agarrar e manter-se na caminhada do mero estar.

A fala de Márcio revela um desejo de pensar a escola diferenciada num espaço de legitimidade, que é o poder ser igual e o ser diferente. Tal concepção identitária é expressa na alteridade indígena desenvolvida por Castro (2002), no qual a diferença atrai o estar sendo indígena. O que a escola diferenciada almeja é o encontro de culturas, um encontro de algo que é exterior.

O reconhecimento do outro nas relações deve ser buscado com respeito e dignidade, pois integram uma circularidade, que passa por seu necessário pressuposto: a interação. A interação é conflituosa e provocadora, faz parte do processo social, pois cada um de nós é sujeito diferente em função daquele com quem nos relacionamos.

E o encontro de pensamentos culturais entre o ser ocidental e o estar sendo ameríndio é de grande valor para nossa afirmação de identidade.

"En este punto logro el equilibrio, una especie de remanso en el cual digo así es, con lo cual me ubico y, por lo tanto, procedo, y acudo a lo oficina de Extensión Agrícola. Mi límite, en suma, está em la situación objetiva y a partir de ahí modifico la realidad" ( $\mathrm{KUSCH}, 2012$, p. 49).

O Estar aqui é anterior ao Ser alguém, por isso mesmo o Ser tende a ser fagocitado, como tudo o que tende a uma atitude absoluta e não têm suas raízes na vida (KUSCH, 1999). O Ser é uma pura construção e, portanto, pode ser destruído. Kusch traz que a prova disso está no Ocidente, 
quando no afã de conseguir a eternidade uniforme e o mundo absoluto e essencial sobre a base de excesso de tensão, com a exclusão do diabo, com a criação das cidades e dos objetos, teve chegado ao cume e agora não pode retornar ao mero Estar para ser absorvido a fim de renovar sequer suas forças.

As escolas diferenciadas têm possibilitado uma reflexão acerca da interciência abordada por Boaventura (2010) que provoca a discussão dos conhecimentos indígenas como dimensão científica e do campo da educação como espaço de problematização e legitimidade do sentido do que as escolas vão definindo como o que é ciência e o que é cultural, bem como que espaço ocupa nos currículos obrigatórios e complementar.

A questão que os Guarani, ao fagocitarem a escola, nos provoca é o estar sendo ciência: o medo de que o índio seja engolido pelo branco. $O$ medo de que a escola tradicional engula o modelo escolar indígena, que possui outros modos, serve mais como uma apropriação e reflexão para os Guarani, como bem falou Vander, um professor Guarani, em uma de nossas reuniões: "nós temos escola diferenciada, sim! Nós somos reconhecidos na rua como índios, mesmo falando e entendendo português, porque está nos nossos traços, na nossa face, no nosso intimo, a essência do índio! Nós somos diferentes e sempre seremos." Para além de demarcar a diferença, as lideranças, os professores indígenas e não indígenas, tanto das escolas diferenciadas, - quanto das escolas de ensino médio e da Universidade -, estão sendo desafiados, ao tempo em que envolvidos em uma discussão, que é de legitimidade científica, de espaço de formação e de aprendizagem acerca de uma compreensão de alteridade que atrai e é atraída e, que provoca uma transformação de uma educação da indiferença e da paralisia (CASTRO, 2002).

Há uma polarização, sim, num diálogo de encontros e desencontros que querem seguir aprofundando. Os conflitos, as discussões que surgem estão servindo para aprofundar a relação ente pensamento ameríndio e pensamento ocidental, entre professores e estudantes indígenas e não indígenas, entre concepções de ciência, de conhecimentos.

Encontro que envolve saberes Guarani que tem na Tekoa ${ }^{5}$ sua ciência, saberes do estar sendo de Kusch e saberes ocidentais da nossa escola tradicional. Um projeto de escola intercultural é um diálogo de sujeitos. Uma troca que está invertendo o processo; ao contrário de ir do pensamento para a realidade, buscamos entrar na realidade da aldeia vivenciando o modo de ser e estar, e compreendendo, a partir dela, aquilo que vamos fazer. A nossa vivência é uma prática pedagógica de encontros e não de convenções. Há um desejo de todos, e por isso, tudo está acontecendo. O que significa dizer que estamos primeiro conhecendo a cultura indígena local, respeitando, indagando e criando conjuntamente.

Há um desejo dessas lideranças Guarani de integrar, de não ficar à margem da historia também. O Vander, professor indígena, diz que: "eles querem a escola, que é importante para o guarani entrar nesse mundo." O indígena quer se misturar, no estar sendo em diálogo com o ser ocidental. É uma forma de constituírem-se na alteridade, numa compreensão trazida por Castro (2002) acerca da identidade dos indígenas, o quanto são abertos e necessitam do diferente, para tornarem-se mais eles mesmos. E a construção das escolas diferenciadas, nessas aldeias, tem sido a expressão do diálogo entre professores e de concepções que falam de um viver seminal e de um viver ocidental e de aprendizados de alteridade.

\footnotetext{
${ }^{5}$ Termo Guarani para designar Aldeia, morada.
} 
O pensar seminal, desenvolvido por Kusch (2012) em suas pesquisas com os povos indígenas, possibilitou-nos pensar acerca do conceito de vivência desenvolvido por Pinho (2003) no sentido de ser uma experiência integrada entre o pensar, sentir e atuar. De voltar a considerar o conhecimento desde as condições vivas da realidade do mundo e de nossa própria realidade psíquica, desde a consideração de um homem concreto, sensível e não puramente intelectual, que se relaciona com uma realidade igualmente concreta e viva, que fala de um viver seminal.

\section{RESULTADOS}

O processo de pesquisa tem gerado alguns resultados significativos para os Guarani e para a Universidade. Percebemos o quanto os Guarani têm nos ajudado a olhar para o conhecimento como um pensar e um viver seminal. Assim, são os Guarani em nosso encontro intercultural, que vem sobrevivendo há mais de 500 anos e que tem nos ajudado a pensar aspectos educativos da nossa formação humana e profissional, de nossos conhecimentos, tão distintos e que necessitam encontrar-se.

Nesse encontro, que realizamos entre Guarani e não indígena, sentimos a diferença dos opostos, como a educação européia e a educação indígena, a escola e a comunidade, e que podem andar, não necessariamente em sentidos contrários, mas em equilíbrio e que tem nos levado a compreender a formação como uma aprendizagem amorosa, sensível e reflexiva. Uma educação que nos encoraje a lidar com as incertezas, com tudo aquilo que desafia a nossa própria cultura e educação.

Os Guarani, professores indígenas e não indígenas das escolas diferenciadas têm participado de eventos nas Universidades (UNISC e UFRGS), como palestrantes, debatedores e ouvintes num processo de autoria e de reflexão intercultural. Por outro lado, os estudantes e professores universitários estão sendo provocados em seus modos de vida, gerando novos conflitos e diálogos de muita potência para a própria formação universitária.

Outro aspecto gerador de muitos diálogos é a produção de um livro acerca da infância Guarani, no qual universitários e indígenas exercitam um caminho conjunto de aprendizagem, de escrita e de transformação, entre pensamentos aparentemente contrários, como é o do viver seminal que nos puxa para a terra, para o fluxo da água, para um tempo cíclico e contínuo e o do viver ocidental, que nos orienta na direção da sistematização, da ligeireza, do tempo dividido. Além de pensarmos conjuntamente novas ideias inspiradoras para a educação, como a que estamos gerando, temos construído espaços de trocas efetivas, afirmando e valorizando as aldeias como campos de aprendizagens e a convivência intercultural como fonte produtora de novos conhecimentos.

\section{REFERÊNCIAS BIBLIOGRÁFICAS}

1. BERGAMASCHI, M. A. (orgs). Educação indígena sob o ponto de vista de seus protagonistas. Porto Alegre: Evangraf, 2013.

2. CASTRO, E.V.de. A inconstância da alma selvagem e outros ensaios de antropologia. São Paulo: Cosac \&Naify, 2002.

3. FLORENCIA, K. El hedor y los márgenes: la militância barrial (territorial). In: TASSAT, J. A.; 
PÉREZ, J. P. (orgs). El Hedor de America, Reflexiones interdisciplinares a 50 años de la America Profunda de Rodolfo Kusch. EDUNTREF, 2013.

4. KUSCH, R. America Profunda. Buenos Aires: Editorial Biblos, 1999.

5. Esbozo de una antropologia filosofica americana. Buenos Aires: Ediciones Castañeda, 2008.

6. El pensamento indigena y popular enamerica y lanegación del pensamiento popular. Rosario: foundación A. Ross, 2012.

7. MACEDO, R. S. A etnopesquisa critica e multirreferencial nas ciências humanas e na educação.Salvador: EDUFBA, 2004.

8. MELIÀ, B. Educação guarani segundo os Guarani. In D. R. Streck (Org.), Fontes da pedagogia latino americana: uma ontologia. Belo Horizonte: Autêntica Editora, 2010, p.37-54.

9. MENEZES, A. L. Diário de campo. Santa Cruz do Sul: 2013.

10. PINHO, A. M. de M. El valor ético del arte. Buenos Aires: Libris, 2003.

11. SANTOS, B. de S. \& MENESES M. P. (orgs.). Epistemologias do Sul. São Paulo: Cortez, 2010.

12. VICOSA, R. M. de Oliveira. Diário de campo. Santa Cruz do Sul: 2013. 